\title{
The influence of immersion and presence in early stage engineering designing and building
}

\section{Citation}

Faas, Daniela, Qifang Bao, Daniel D. Frey, and Maria C. Yang. 2014. “The Influence of Immersion and Presence in Early Stage Engineering Designing and Building." AIEDAM 28 (02) (May): 139151. doi:10.1017/s0890060414000055.

\section{Published Version}

doi:10.1017/s0890060414000055

\section{Permanent link}

http://nrs.harvard.edu/urn-3:HUL.InstRepos:25586349

\section{Terms of Use}

This article was downloaded from Harvard University's DASH repository, and is made available under the terms and conditions applicable to Other Posted Material, as set forth at http:// nrs.harvard.edu/urn-3:HUL.InstRepos:dash.current.terms-of-use\#LAA

\section{Share Your Story}

The Harvard community has made this article openly available.

Please share how this access benefits you. Submit a story.

\section{Accessibility}




\title{
The Influence of Immersion and Presence in Early Stage Engineering Designing and Building
}

\author{
Daniela Faas \\ School of Applied Science and Engineering \\ Harvard University \\ Cambridge, MA USA \\ Qifang Bao \\ Department of Mechanical Engineering \\ Massachusetts Institute of Technology \\ Cambridge, MA USA \\ Daniel Frey \\ Department of Mechanical Engineering and Engineering Systems Division \\ Massachusetts Institute of Technology \\ Cambridge, MA USA \\ Maria C. Yang \\ Department of Mechanical Engineering and Engineering Systems Division \\ Massachusetts Institute of Technology \\ Cambridge, MA USA
}

An experiment was conducted to assess presence and immersive tendencies within the context of a design-and-build activity. The central research question is: Do designers who are more engaged in design activity, as measured by standard presence and immersive tendency questionnaires, produce better designs? Participants were instructed to build a vertical displacement mechanism for a PingPong ball. The design outcome indicator was maximum vertical displacement (height) of the plastic ball. The average height measured was $21.43 \pm 5.46 \mathrm{in}$. A correlation between presence and design outcome was found to be statistically significant $(\mathrm{p}=0.014)$, but the experiment did not reveal a correlation between immersive tendencies and design outcome. Results indicate that designers' sense of immersion and presence ranged widely. This study suggests that some level of presence is linked with better design.

\section{Introduction}

During the early stages of design, designers may employ a range of tools and techniques while involved in key activities such as generating, selecting, and evaluating design concepts. These tools may 
include sketching, building prototypes, other types of modeling (such as CAD), or verbal or written text about a design idea. In particular, the process of constructing physical prototypes of a design idea can uncover important design issues [1] that may not be apparent from a 2D representation such as a sketch. Furthermore, the hands-on experience of manipulating materials for a prototype, including fabrication of components and assembly, provides the designer with an opportunity to reflect and interact with a design, particularly to explore the space of design concepts [2], generate new designs [3] or winnow down the design space [4]. This paper examines the role of immersion and presence, both measures of an individual's engagement in an activity. This study explores how immersive tendencies may be involved in early stage design activities, specifically prototyping. In other words, this research examines how deeply engaged an individual is in the act of designing relative to the end product of an early design exploration. Presence is defined as the extent to which a simulation is able to induce a feeling of being "present" in the moment while in an environment [5-7]. Presence is described as a sensation, which is a function of the experienced medium. Witmer and Singer [8] suggest several factors such as selective attention, involvement and immersive response as necessary to experience presence. Immersive tendency also relates to the sense of involvement in an activity but is considered a trait and relates to the tendency to behave playfully and to become involved in a continuous stream of stimuli [9]. A virtual reality system is considered immersive because it immerses a user's body in the virtual environments. Immersion can lead to presence, which is the user's sense of being in the virtual environment.

Applying presence and immersion evaluations to design activities allows a novel way of looking at how designers design and build. Specific questions this research examines include the following:

\section{What is the nature of immersion and presence in the context of early stage engineering design?}

How are immersive tendencies and presence linked to the design process? Presence and immersion are important to virtual reality applications and measure how well a person "responds" to the virtual environment and we believe these tendencies have relevance to how designers may perform in the real world. Engineering design has developed its own criteria to gather information during the design process. In studies of creativity, Csikszentmihalyi discussed the notion of "flow" that experts experience 
while absorbed performing an activity that allows them to lose sense of time [10]. If we assume that presence and immersion are related to this notion of flow, can it be that designers experience a similar feeling while designing? Verlinden, et al [11] have studied the use of augmented virtual reality systems to support design property, but in this paper we consider presence and immersive tendencies at a more basic level.

2. Do immersive tendencies correlate with better design? If it is true that people who are more engaged in a design and prototyping activity have higher levels of presence and immersion, then does more engagement mean better performance? Not being engaged in an activity would seem to mean poorer performance, but is the converse true?

Design is a complex activity with many potential factors that can influence its outcome. Discovering a link between the way we design and our immersive and presence tendencies might shed some light on what design tools are useful and what level of presence should be cultivated during the prototyping stage to produce better designs.

\section{Background}

Presence and immersive tendency have been studied extensively in the field of virtual reality [12]. In order for virtual reality to seem real, the environment must respond authentically to the user's actions. Virtual reality technology allows the user to be present in a virtual world and to be mentally immersed while the virtual reality system senses the user's position and actions and responds to one or more of the user's senses. The key elements of the virtual reality experience are the virtual world, immersion, sensory feedback and interactivity.

Presence can be a major factor that determines the quality and success of a virtual environment implementation. Witmer and Singer [8] suggest several factors such as selective attention, involvement and immersive response as necessary to experience presence. Others identified different factors contributing to presence such as spatial presence, quality of immersion, involvement, drama, and interface awareness, exploration of virtual environment, predictability and interaction, realness [5]. How- 
ever, Inkso [6] points out that the problem with any questionnaire is that two people may have different responses in the same environment and that the questionnaire measures the user's perception of system properties, rather than psychological presence [13].

The tendency to experience presence is considered a personal characteristic of the user. Witmer and Singer therefore suggested another factor in presence measurement called immersive tendency. This can be a personal tendency to be drawn into reading a book or involved in another activity. Research by Samana et al. [14] determined that personality traits such as empathy correlated with the experience of presence. Several studies have shown that presence tends to increase as the fidelity of a reproduction or simulation of the physical world increases. This can be done with high-resolution displays, physics simulation, sound location or other measures.

The Presence Questionnaire (PQ) has been used to compare presence in a real office environment and virtual reality office. The study found that there was no difference in presence between the two environments. The researchers then tried to explain why people felt equally present in virtual reality and "real" reality. Usoh et al. write, "In the real-world, since there is no doubt that the individual is present in the obvious sense, it becomes reinterpreted as the sense of involvement, the lack of isolation, perhaps the degree of comfort" [15]. The questionnaire has been criticized in the way it correlates individual scores with the sum of scores $[9,13]$. However, this questionnaire was chosen for the experiment in this paper because it standardizes the information gathering process for this study, and an example question is shown in Figure 1.

Immersive tendency is considered a trait and relates to the tendency to behave playfully and to become involved in a continuous stream of stimuli. Witmer and Singer's Immersive Tendencies Questionnaire (ITQ) contains 29 items [8]. For example, "How mentally alert do you feel at the present time?" tests the current "state" of the user and "Have you ever remained apprehensive or fearful long after watching a scary movie?" tests the trait.

Both questionnaires use a seven-point scale format. Each item is anchored at the ends by opposing descriptors. The instructions asked respondents to place an " $\mathrm{X}$ " for each question in the appropriate box. 


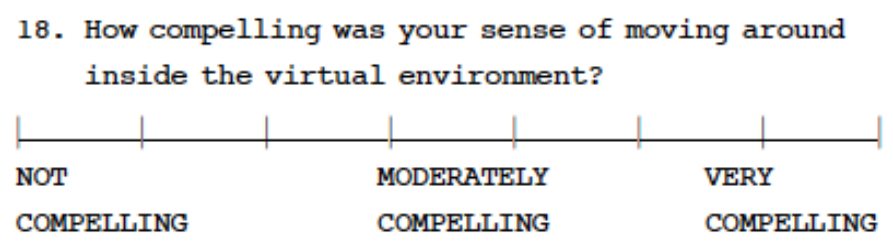

Figure 1. Example question from the Presence questionnaire [8]

Subscales for both ITQ and PQ were identified from the previous analysis by Witmer and Singer. The subscale labels are loosely based on the content of the questionnaire items in their cluster. The ITQ contains three subscales: involvement, focus and games. Subscales for the PQ include involvement, sensory fidelity, adaptation/immersion and interface quality. Other researchers have tried to qualitatively define immersion with taxonomies [16, 17], but the ITQ and PQ developed and revised by Witmer and Singer continue to be the standard in virtual reality research.

These questionnaires have been used extensively to assess immersion and presence in many applications. Pausch $e t$ al. [18] used these questionnaires to compare a virtual reality interface with a "real" stationary monitor and a hand-based input device. Users completed a search task faster with the virtual reality setup than users with monitor and hand-held device. Banerjee et al. used their own modified version of the ITQ and PQ to show that virtual environments are advantageous for conceptual design reviews over traditional methods $[19,20]$.

Other studies compare the performance of multiple immersive displays and input for virtual reality applications devices [21]. Robertson et al. determined that head-mounted displays performance characteristics did not transfer to desktop virtual reality [22]. Stothard et al. used immersion and presence levels to assess mine workers in interactive training [23]. Nichols et al. compared the use of direct performance measures and rating scales to evaluate presence for different virtual environments [24]. Virtual reality has been used in engineering design to facilitate interaction with models, assembly prototyping and other uses. Examples of engineering design in virtual reality include hose routing planning, visualizing computational fluid dynamics, and product reviews. In assembly prototyping, it has been shown that the use of virtual environments helps users perform assembly tasks [25]. This study differs from prior work in that it considers the role of immersion and presence in the process of design and assembly, not as a comparison with virtual experiences. 


\section{Methods}

\section{Participants}

The study involved 30 graduate and undergraduate students in a Mechanical Engineering department at a US university. The sample population was composed of 14 females and 16 males with ages ranging from 18 to 31 years (mean of 23 years). The participants reported an average of 7 years of design experience in the classroom or in practice. On average, they spend 11 hours per week on design related activities while at school. In addition, the students took 5 design classes during their studies. No compensation was provided to the participants.

\section{Procedure}

The study consisted of three phases that took less than one hour to finish. During the introductory phase, participants were presented with the informed consent form by the staff and given enough time to ask questions and fill out the form. Users received an overview of the study. In addition, participants were asked about their age, gender, education level and duration of experience with designs. Next, they were asked to complete the immersive tendency questionnaire. No training was given. The secondary phase was the design and building phase, which is described in the next section. The final phase required the participants to fill out the presence questionnaire to assess how engaged they were in the design and build activity. All participants filled out a debriefing questionnaire. During the post-completion survey, participants were asked how frustrated or calm they felt during building. The participants also wrote down how many concepts they generated in their mind before deciding on their final design.

\section{Design Activity}

Individual participants were instructed to build a vertical displacement mechanism for a Ping-Pong ball in 30 minutes. None of the participants were given any building instruction. A guideline specified that the design had to use a rectangular plate as the base for their mechanisms. They could place the Ping-Pong ball into their mechanism, but ultimately the measured height would be determined by the initial and final position of the ball. They had to use a 500gr weight as an energy source and could on- 
ly use their hands to activate the mechanism. Each participant built his or her device using only elements from a kit containing a wide variety of parts and materials. The kit contained 72 assorted aluminum and stainless steel components along with axles, string, rubber bands, fasteners and tools (Figure 2). The rules did not prevent the rubber bands to be used as an additional energy source. The metal pieces were purchased from Gear Educational Systems, LLC in Hanover, MA (www.geareds.com).

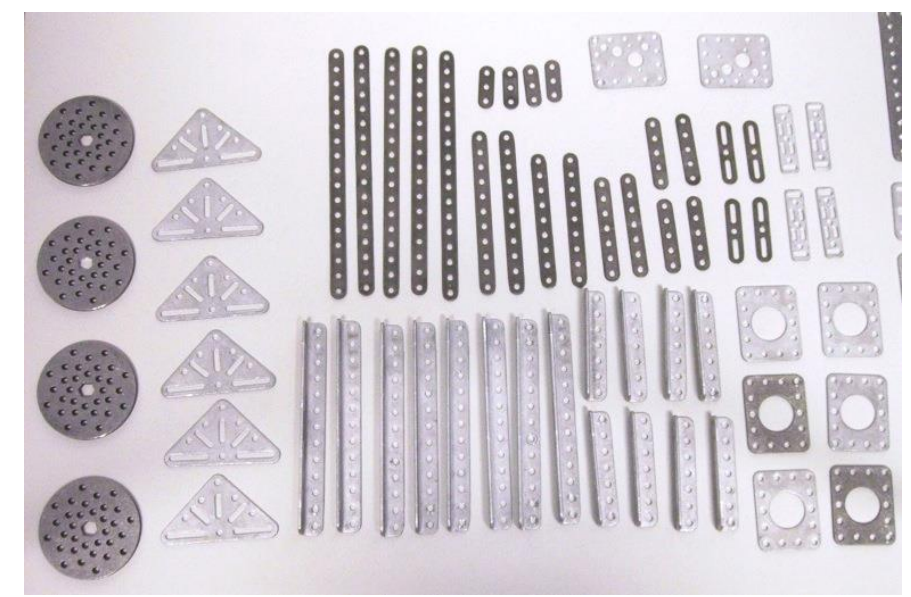

Figure 2. Sample of parts available to participants for design and assembly

They were not permitted to build a mechanism that would bend or plastically deform the aluminum hardware in any way. A set of tools was made available to participants to assemble their designs. Tools that were most heavily used were hex wrenches, scissors, and screwdrivers (Figure 3). The tools were laid out in front of the participants in plain view on a table. The rules did not specifically exclude using the table to add height to the design.

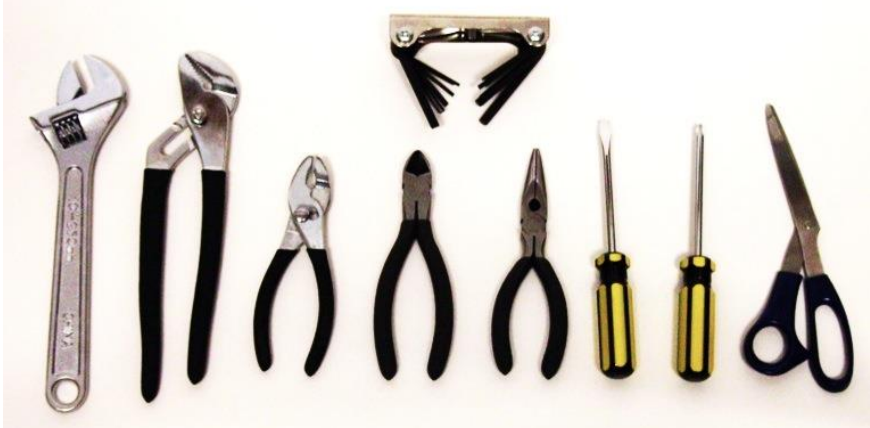

Figure 3. Tools available to participants for assembling parts 
Participants had access to all structural components as well as tools during the activity. The participants were instructed not to make drawings during the design activity so as to isolate the participants' efforts to only design and assembly. One reason the experiment asked participants to build from prefabricated kit parts rather than ask participants to design and fabricate custom parts was to reduce the advantages that some participants might have in fabrication skill. They were also not allowed to use SolidWorks or any other CAD software. A timer was also visible to the participants at all times. The maximum vertical height of the Ping-Pong ball was measured at the end of this activity. The number of components used in the design was not counted.

\section{Design Outcome Evaluation}

Several indicators of design outcome were employed. The first was the maximum horizontal displacement of the Ping-Pong ball by measuring the initial and final positions. The second indicator was whether the structure was able to support the $500 \mathrm{gr}$ weight. The resulting designs were assessed for their novelty as measured by Shah, et al.'s metric [26]. Finally, a debriefing survey was administered to gauge participants' sense of calmness and frustration during the design activity.

\section{Results}

All 30 participants completed a mechanism within the allotted 30 minutes. The average height measured was $21.43 \pm 15.46 \mathrm{in}$. The minimum height was 0 in (non-functional design) and the maximum height was 64 in.

The 30 resulting designs could be categorized into 3 types of mechanisms: catapult, fulcrum and pulley. Figure 4 shows a box plot distribution of each of the mechanism heights. Thirteen participants used a pulley system $(18.19 \pm 4.46$ in) and 7 used a system that implemented a fulcrum $(23.79 \pm 6.07$ in) to lift the ball. An additional 10 participants used a catapult $(21.85 \pm 5.08$ in) to displace the ball. A two-way Analysis of Variance (ANOVA) was used to test the difference in performance among the three types of structures and the differences were not found to be significant, $F(2,27)=0.3129, p=$ 0.734. A conclusion is that, in this experiment, the implementation details were a stronger determinant of performance than the concept chosen. 


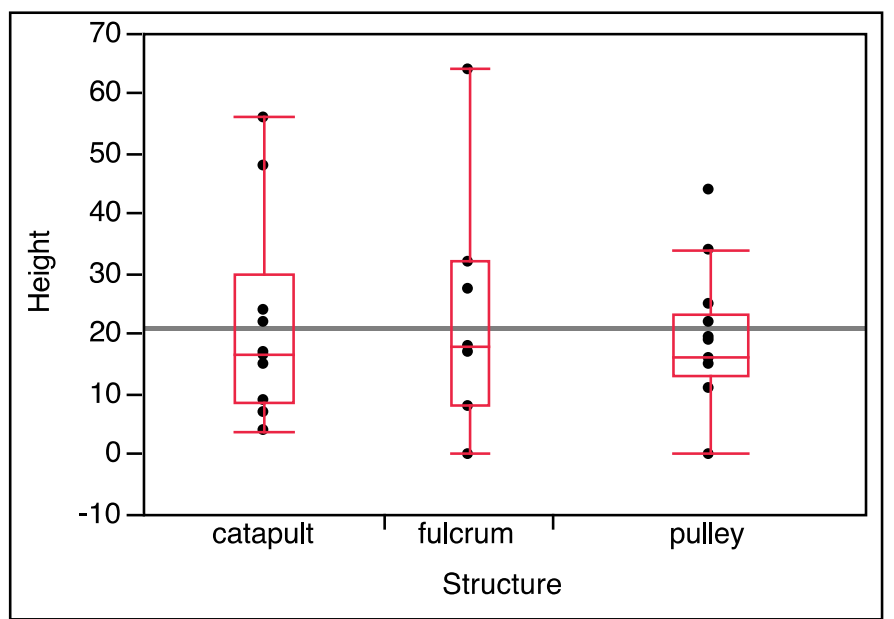

Figure 4. Box plot of the mechanism height vs. structure

The pulley system used the string that was provided to allow for the ball movement. Ball attachment to the mechanism could also be placed into two categories. One was a loose connection (ball was placed in some type of basket or other holding mechanism), but there was no physical connection between the ball and the support structure. The second connection was made either with string or with rubber bands or a combination of rubber bands, string and metal pieces (Figure 5).

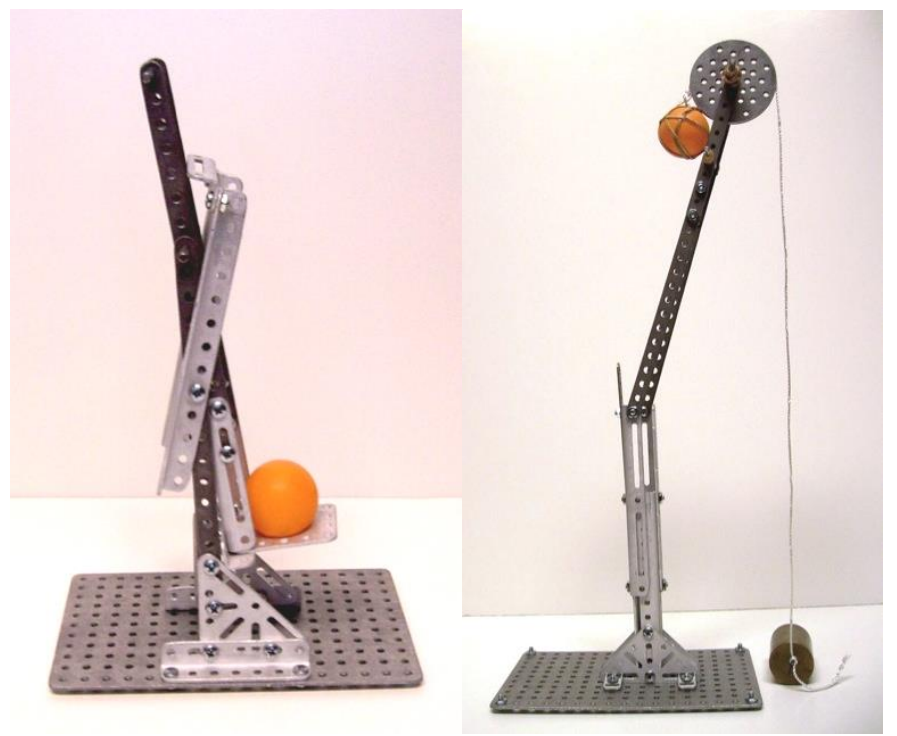

Figure 5. Example of a fulcrum design (left) and pulley system (right) 


\section{Presence}

The responses to the presence questionnaire were analyzed for all 30 participants. The mean of the presence questionnaire was $106.32 \pm 18.05$, with a maximum score of 133 and a minimum of 66 . As a reference point, a score of 100 means that an individual has a high sense of presence. In this experiment, presence scores and height had a correlation coefficient of 0.42 , which was statistically significant $(\mathrm{p}=0.014)$ (Figure 6).

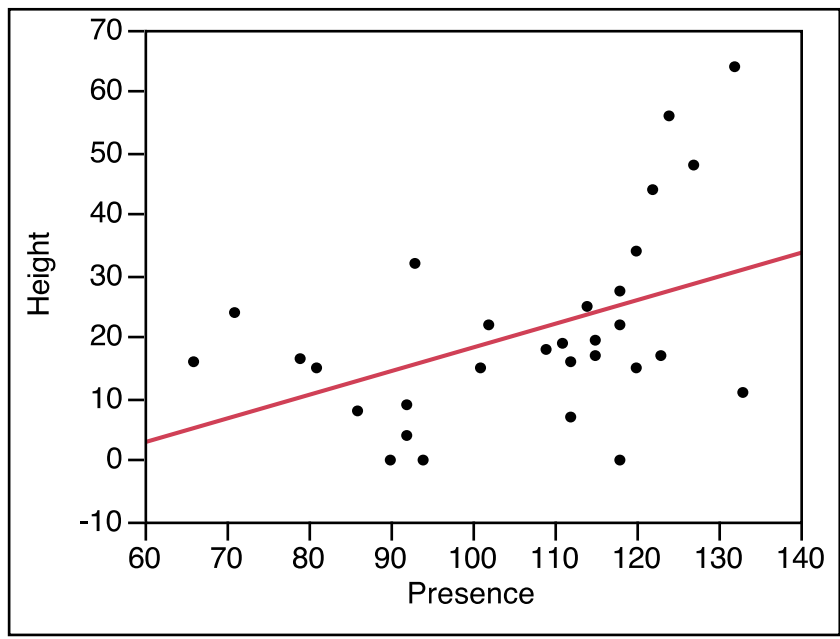

Figure 6. Correlation between presence and mechanism height (linear fit)

Participants with higher presence scores tended to attain a higher ball height. This meant that people who were more engaged "in the moment" produce more effective designs. This finding is consistent with our initial expectation of the link between presence and design outcome.

\section{Immersive Tendencies}

The responses to the immersive tendency questionnaire were analyzed for all 30 participants. Participants scored (on the combined total) $107.27 \pm 16.60$, with a maximum score of 147 and a minimum of 73. A higher score on the ITQ means a higher level of immersion. An F ratio of $0.499(\mathrm{p}=0.486)$ did not show a statistically significant correlation between immersive tendencies and design outcome (Figure 7). 


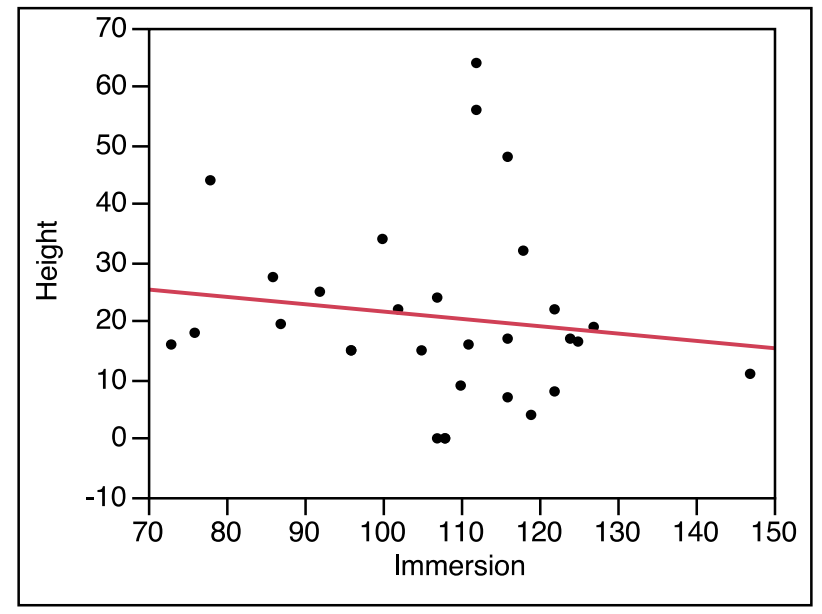

Figure 7. Immersive tendency vs. mechanism height (linear trend line shown)

This experiment suggests that immersive tendencies are not linked to design outcome for this type of design task. It had been expected that participants would build multiple concepts and test the performance of each. This iterative process might then suggest reflection in and excitement about the design process. However, participants were not told explicitly to explore multiple design concepts. Our observations of the participants showed that they generally spent all of their time steadily building a single design. It's not clear why they did not explore more designs in the 30 minutes, though we conjecture that it might be because they felt time pressure, or didn't do so because we didn't instruct them to. This informal observation of their limited iteration is consistent with the measured immersive tendency.

\section{Immersion vs. Presence}

Because immersive tendency can lead to presence, the correlation between immersion and presence is examined. One might hypothesize that a participant with a higher immersive tendency would also score higher on presence. 


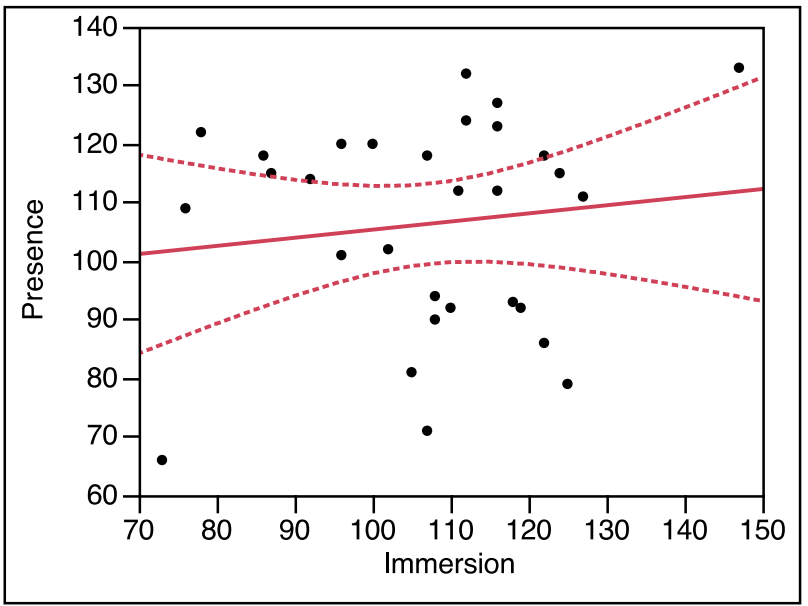

Figure 8. Immersion vs. presence

Immersion versus presence is shown in Figure 8. An F ratio of $4.623(\mathrm{p}=0.502)$ was determined for the correlation of immersion and presence. This experiment did not reveal any significant correlation between immersion and presence. Previous research efforts [27-29] suggest that higher levels of immersion lead to an enhanced level of presence. This experiment did not confirm those studies, perhaps because of the physical nature of the prototyping environment made available to the subjects, rather than a virtual prototyping environment.

\section{Types of designs}

Only three types of designs (fulcrum, catapult, pulley) were used by the sample of participants. A comparison between the type of structure and presence did not reveal a statistically significant difference among the mean performance in each class of designs. 


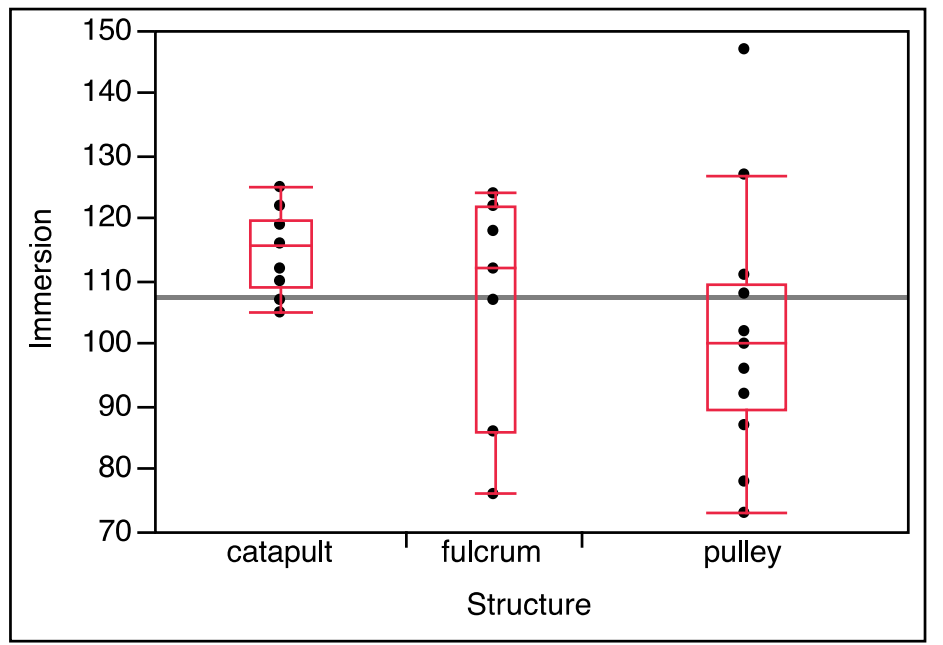

Figure 9. Type of design (fulcrum, catapult, pulley) vs. immersion

Tukey post-hoc comparisons of the catapult $(\mathrm{M}=114.8, \mathrm{p}=0.069)$, fulcrum $(\mathrm{M}=114.8, \mathrm{p}=0.302)$, and pulley $(\mathrm{M}=114.8, \mathrm{p}=0.557)$ indicate that building a certain structure did not result in a higher level of immersion (Figure 9). People that built a catapult had a higher level of immersion than participants that built a pulley, but the difference was not statistically significant. The survey after the completion of the design activity did not capture how the participants felt about the difficulty level of their design and whether they perceived their chosen design structure to be easier to build than other structures.

\section{Novelty of designs}

The novelty of the designs was assessed based on methods introduced by Shah, et al. [26]. Novelty was measured in the following way. Each design was divided into four attributes: ball-raising mechanism, ball attachment method, footprint structure, and structural rigidity. Each attribute was given a novelty score $S_{i}$ and a weight $p_{i}$, the overall novelty of ideas within each group can be computed by:

$$
\mathrm{M}_{\text {novelty }}=\sum_{\mathrm{i}=1}^{4} \mathrm{~S}_{\mathrm{i}} \mathrm{p}_{\mathrm{i}}
$$

For each design, the solution of every attribute was categorized. The novelty score $S_{i}$ was given by:

$$
S_{i}=\frac{T_{i}-C_{i}}{T_{i}} \times 10
$$


where $T_{i}$ is the total number of solutions produced for the $i^{\text {th }}$ attribute and $C_{i}$ is the count of the current solution for that the $\mathrm{i}^{\text {th }}$ attribute. Multiplying by 10 normalizes the expression. The average novelty score was $25.2 \pm 2.3$. Note that this score is not an absolute measure.

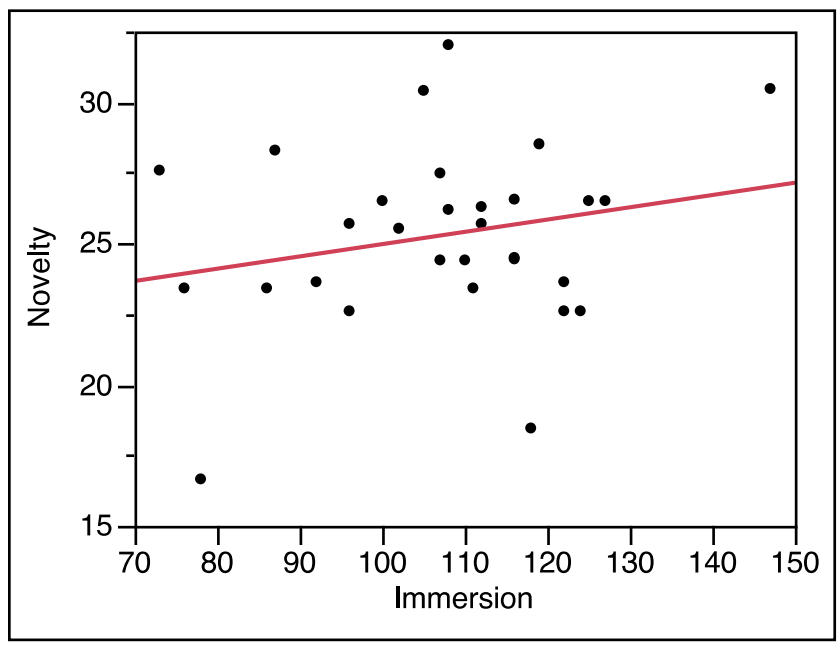

Figure 10. Novelty score vs. immersion

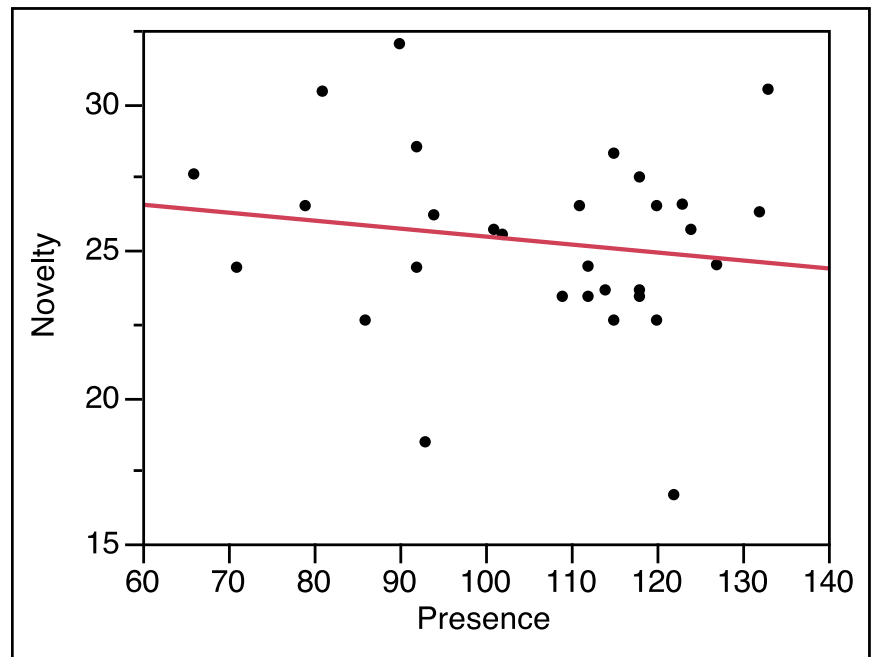

Figure 11. Novelty score vs. presence

Figures 10 and 11 show the novelty score versus immersion score and presence score respectively. No significant correlations are found, with ANOVA p-value for the two fit equal to 0.2317 and 0.4210 , respectively. 


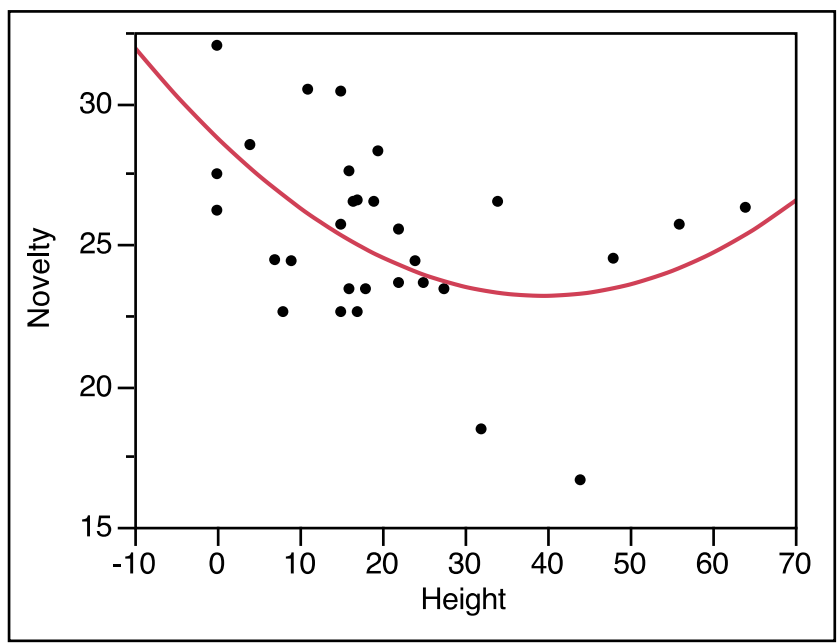

Figure 12. Novelty score vs. height

Figure 12 shows the novelty score plotted against the height of the raised Ping-Pong ball. A second order fit can be found between the two data set with an ANOVA p-value $=0.0197$. From the plot we can see that designs judged to be the most novel frequently did not work well (failed to raise the ball especially high). However, those that did work well (raised the ball to a high position) generally had higher novelty scores. In other words, novelty seemed to be important creating a successful design, but ideas that were the most novel (at the extreme end) were not as successful as those that were slightly less novel. Designs of average novelty generally functioned well. These were lower risk ideas with a lower chance of failure, but were also less likely to be the most successful.

\section{Surveyed Qualities}

Surveyed qualities such as frustration, engagement were recorded in a post-completion survey. Participants were asked how frustrated or calm they were during the design activity at any point. The participants rated their level of frustration from highest (1) to lowest (7). 


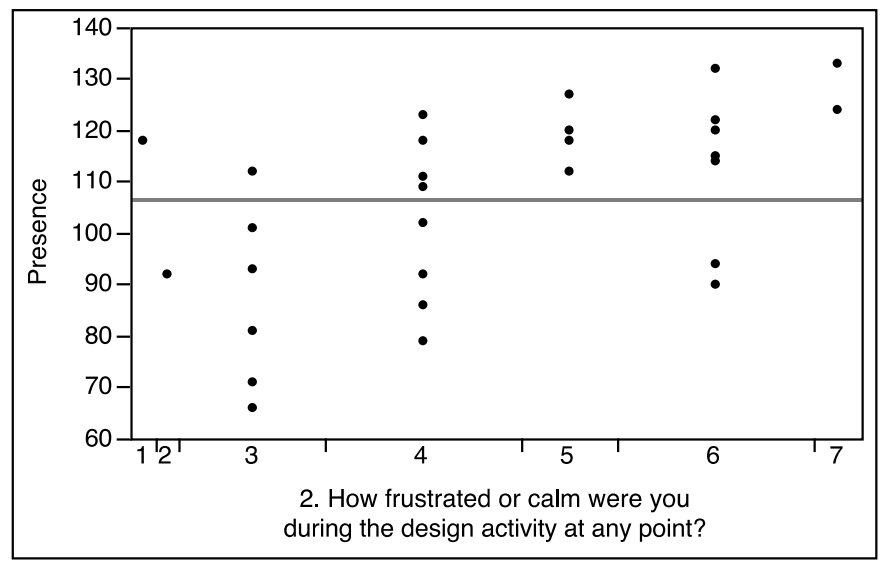

Figure 13. Surveyed frustration vs. presence

Figure 13 shows the surveyed frustration levels and the presence score. To determine if there is a correlation between frustration levels and presence, it was assumed that the frustration level was a rating scale. The participant's response to frustration level with a rating of 4 is between a rating of 1 and a rating of 7 , but they might not think it is exactly halfway between. The correlation coefficient was determined to be 0.502 with a corresponding $\mathrm{p}$ value of 0.005 . There seems to be a positive correlation where participants that felt calm during the design activity experienced a higher level of presence. No correlation between immersion and level of frustration was found. Additionally, no correlation between the type of design and surveyed qualities (frustration, engagement) were found.

In addition to the surveyed qualities, the participants were asked how many concepts they generated before settling on their final design. In general, most participants explored $2.9 \pm 1.7$ ideas during the design period (interquartile range 2.3-3.5). Only 1 participant explored more than 10 ideas. A bivariate linear fit with a resulting $\mathrm{F}$ ratio of $0.665(\mathrm{p}=0.422)$ of showed a no correlation between immersive tendencies and number of ideas generated. There correlation between presence and number of ideas resulted in an F ratio of $1.049(\mathrm{p}=0.314)$. Participants that explored a higher number of concepts had a tendency for higher levels of presence.

\section{Gender}

Performance of the design activity between genders was analyzed using a one-way ANOVA. The design outcome for male participants was $22.61 \pm 4.23$ in and for female participants $19.06 \pm 3.74$ 
in $(\mathrm{F}=0.373, \mathrm{p}=0.546)$. Female participants scored $108.29 \pm 4.50$ the immersive tendency questionnaire while males scored 106.38 $\pm 4.22(\mathrm{~F}=0.096 \mathrm{p}=0.759)$. In the presence questionnaire, Male participants scored $103.25 \pm 4.51$ and female participants scored $109.86 \pm 4.82(\mathrm{~F}=1.000 \mathrm{p}=0.336)$. Figure 14 shows the height outcome of the design for each gender.

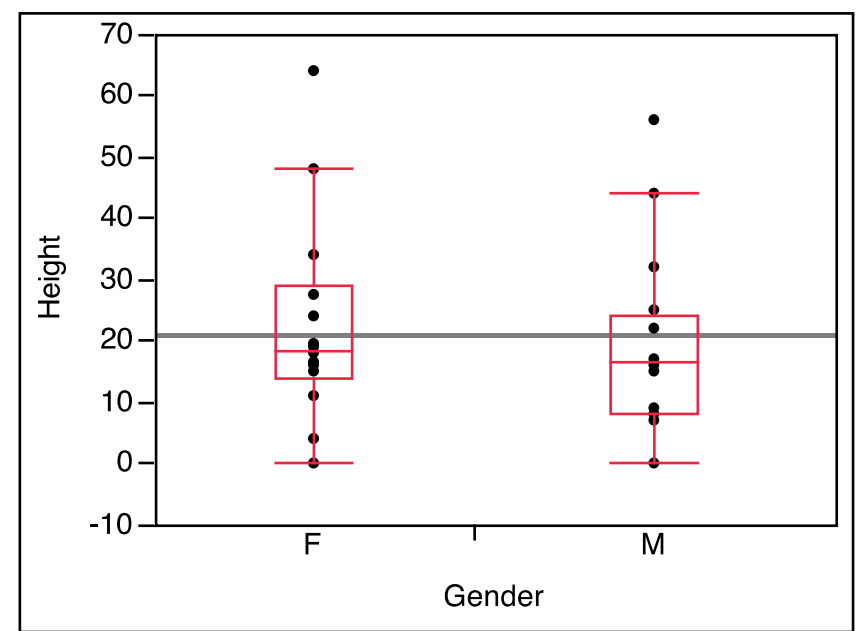

Figure 14. No significant height differences between female and male participants observed

Statistically speaking, there are no significant differences between the design outcome, immersive tendency and presence score and gender.

During the debriefing, participants were asked if they felt frustrated at any point during the design activity. The participants evaluated their frustration at 4.5 (interquartile range, 3.25-6), indicating a low level of frustration. They reported that they were highly engaged during the activity at 5.87 (interquartile range, 5-7). On average, each participant explored 3 different concepts during the design activity (in their head or the ones that were built). Furthermore, the participants were satisfied with their final designs (4.2, interquartile range 3-5) and would continue on their designs if they had been given more time (6.7, interquartile range 7-7).

\section{Discussion}

\section{What is the nature of immersion and presence in early stage design activity?}

Results indicate that designers' sense of immersion and presence ranged widely, as well as their sense of frustration and calmness while performing the design activity. 


\section{Do immersive tendencies correlate with better design?}

Significant correlations between presence height that a ball could be raised were found, but not between immersion and height. This finding suggests engagement/absorption is a necessary but not sufficient condition for performance. Just because an individual feels engaged in activity in the present moment doesn't mean he is excited about it or has a sense of playfulness as one might while immersed in an activity.

All participants completed building a mechanism within 30 minutes. Only one participant built a design that was non-functional. In general, simple mechanisms (fewer parts) almost always performed better than more complicated ones. None of the participants tested their designs during the building phase. The only testing of the mechanism was during the actual evaluation period (following the 30 min.). This was primarily due to the time constraint.

Most participants were building right away and did not spend time "playing" around with the building blocks. It seems that most of them were fixed on one design and did not explore further options, which is detrimental to engineering design. Participants decided on one design and tended to stick with it rather than change. Few changes were made during activity, possibly because of the $30 \mathrm{~min}$ time limit. None of the participants dismantled their design and started from scratch again. In addition, despite instructions during the design briefing that no sketching is allowed at any time, a third of the participants asked if they could sketch. While sketching certainly aids in rapid generation of ideas, idea generation was not the focus of this user study.

Most participants felt that if they had a goal to beat, their priorities would have changed. Instead of making a nice looking design (i.e. keep ball horizontal), they would have designed a less "elegant" design if the activity would have been goal oriented. Few asked about using table as advantage and gain extra height. Only 3 asked to use of table to "extend" height to floor because there was no rule on table use.

\section{Conclusion}

The results of this study showed that those who had a higher sense of presence during a design-andbuild activity tended to have better design outcomes. Csikszentmihalyi defines flow to be a deep focus 
on nothing but the activity. A person, doing an activity, is fully immersed in a feeling of energized focus, full involvement, and success in the process of the activity. Flow has a strong, documented correlation with performance enhancement. Understanding the role of immersion and presence in design will provide insights for better design education and better interpretation of observable design activity to understand the design activities and cognitive processes that occur during the design process.

\section{Future Work}

Design is a complex activity with many potential factors that can influence its outcome. In this study, the role of immersive and presence tendency in the design process were considered. Sketching activity may provide a tool with which to observe design thinking and provide more insight into immersive tendencies.

A notable characteristic of this study is that is a design-and-build activity, and there is no fabrication of parts. The design activity was intentionally largely configurational and assembly rather than focused on subtractive or additive fabrication techniques, which means that the participants had to think in terms of how existing parts would fit together rather than design new, custom parts. This immersion and presence tendency might be different if the nature of the design activity required even more such design effort on the part of the participants.

A more comprehensive user study might allow us to gain a better understanding during the debriefing stage to determine whether participants would have made changes to the design.

Future work involves a larger scale study including a sketching activity followed by a building phase as suggested by this survey. This would include observation of a larger population of designers and engineers, which would allow for a more comprehensive analysis of responses and generate a richer profile of immersive tendencies. Sketching should be a highly immersive activity. Limiting the participants to no sketching may have an adverse effect on the ideation process. Sketching allows rapid development of different ideas and designs. However it is unclear what role presence plays in the ideation process, particularly with activities like sketching. 
A larger question also arises from the findings in this work. If designers who experience a high sense of presence during a design-and-build activity tend to produce better designs, future work should consider what conditions could improve a designer's sense of presence. This work could, for example, examine strategies for enhancing a designer's focus during a design or prototyping task, or ways of structuring design-and-build activity to enable a stronger sense of engagement. Future work should also investigate how current design conditions and practices in both the workplace and classroom might undermine the sense of presence during design and prototyping. How does the organization itself, its work environments, and the methods that they use negatively impact the sense of presence?

\section{Acknowledgments}

The work described in this paper was supported in part by the National Science Foundation under Award CMMI-1130791. The opinions, findings, conclusions, and recommendations expressed are those of the authors and do not necessarily reflect the views of the sponsors. The authors would like to thank the Singapore University of Technology and Design (SUTD) for funding in part the research reported in this paper through the International Design Center at MIT and SUTD. This work was also supported in part by a Cummins-Tsinghua Women Fellowship.

\section{References}

1. Ullman, D.G., The Mechanical Design Process. Third edition ed. 2003, New York, NY: McGraw-Hill.

2. Schön, D.A., The reflective practitioner: How professionals think in action. Vol. 5126. 1983: Basic books.

3. Viswanathan, V.K. and J.S. Linsey, Physical Models and Design Thinking: A Study of Functionality, Novelty and Variety of Ideas. Journal of Mechanical Design, 2012. 134: p. 091004.

4. Yang, M.C., A study of prototypes, design activity, and design outcome. Design Studies, 2005. 26(6): p. 649-669.

5. Schubert, T.W., F. Friedmann, and H.T. Regenbrecht. Decomposing the sense of presence: factor analytic insights. in Second International Workshop on Presence. 1999. University of Essex, Colchester, 6th and 7th April 1999.

6. Insko, B.E., Measuring Presence: Subjective, Behavioral and Physiological Methods, in Being There: Concepts, effects and measurement of user presence in synthetic environments, F.D. G. Riva, W.A IJsselsteijn, Editor 2003, Ios Press: Amsterdam, The Netherlands.

7. Insko, M., Physiological measures of presence in virtual environments. ACM Transactions on Graphics, 2001.

8. Witmer, B. and M. Singer, Measuring presence in virtual environments: A presence questionnaire. Presence, 1998. 7(3): p. 225-240. 
9. Mantovani, G. and G. Riva, “Real” Presence: How Different Ontologies Generate Different Criteria for Presence, Telepresence, and Virtual Presence Presence: Teleoperators and Virtual Environments 1999. 8(5): p. 540-550.

10. Csikszentmihalyi, M., Creativity: Flow and the Psychology of Discovery and Invention. 1996, New York, New York: HarperCollins.

11. Verlinden, J., A. de Smit, and I. Horváth, Case-based exploration of the Augmented Prototyping dialogue to support design. Proc. Tools and Methods of Competitive Engineering, 2004: p. 245-254.

12. McMahan, A., Immersion, engagement and presence. The video game theory reader, 2003: p. 67-86.

13. Slater, M., Measuring Presence: A Response to the Witmer and Singer Questionnaire. . Presence, 1999. 8(5): p. 560-566.

14. Samana, R., H. Wallach, and M. Safir. The Impact of Personality Traits on the Experience of Presence. in Virtual Rehabilitation International Conference. 2009. Haifa, Israel.

15. Usoh, M., E. Catena, S. Arman, and M. Slater, Using presence questionnaires in reality. Presence: Teleoperators \& Virtual Environments, 2000. 9(5): p. 497-503.

16. Robinett, W., Synthetic Experience: A Proposed Taxonomy. Presence, 1992. 1(2): p. 229- 247.

17. Zeltzer, D., Autonomy, interaction, and presence. Presence, 1992. 1(1): p. 127-132.

18. Pausch, R., D. Proffitt, and G. Williams, Quantifying immersion in virtual reality. Proceedings of the 24 th annual conference on Computer graphics and interactive techniques, 1997: p. 18.

19. Banerjee, P. and D. Basu-Mallick, Measuring the Effectiveness of Presence and Immersive Tendencies on the Conceptual Design Review Process. Journal of Computing and Information Science in Engineering, 2003. 3: p. 166-169.

20. Banerjee, P., G. Bochenek, and J. Ragusa, Analyzing the Relationship of Presence and Immersive Tendencies on the Conceptual Design Review Process. Journal of Computing and Information Science in Engineering, 2002. 2: p. 59-64.

21. Welch, R.B., How can we determine if the sense of presence affects task performance? Presence, 1999. 8(5): p. 574-577.

22. Robertson, G.G., M. Czerwinski, and M. van Dantzich. Immersion in desktop virtual reality. in Symposium on User Interface Software and Technology (UIST). 1997. ACM Press.

23. Stothard, P., R. Mitra, and A. Kovalev, Assessing Levels Of Immersive Tendency And Presence Experienced By Mine Workers In Interactive Training Simulators Developed For The Coal Mining Industry. SimTec, 2008: p. 1-6.

24. Nichols, S., C. Haldane, and J. Wilson, Measurement of presence and its consequences in virtual environments. International Journal of Human-Computer Studies, 2000. 52(3): p. 471-491.

25. Ye, N., P. Banerjee, A. Banerjee, and F. Dech, A comparative study of assembly planning in traditional and virtual environments. Systems, Man, and Cybernetics, Part C: Applications and Reviews, IEEE Transactions on DOI - 10.1109/5326.798768, 1999. 29(4): p. 546-555.

26. Shah, J.J., N. Vargas-Hernandez, and S.M. Smith, Metrics for measuring ideation effectiveness. Design Studies, 2003. 24(2): p. 111-134.

27. Abuhamdeh, S. and M. Csikszentmihalyi, ntrinsic and Extrinsic Motivational Orientations in the Competitive Context: An Examination of Person-Situation Interactions. Journal of Personality and Social Psychology, 2009. 77(5): p. 1615-1635.

28. Jackson, S.A., P.R. Thomas, H.W. Marsh, and C.J. Smethurst, Relationships between Flow, Self-Concept, Psychological Skills, and Performance. Journal of Applied Sport Psychology, 2001. 13(11): p. 129153.

29. Shernoff, D.J., M. Csikszentmihalyi, B. Shneider, and E.S. Shernoff, Student engagement in high school classrooms from the perspective of flow theory. School Psychology Quarterly, 2003. 18(2): p. 158-176.

\section{Author Biographies}

Daniela Faas is currently the Senior Preceptor in Design-Based Instruction at the School of Engineering and Applied Science at Harvard University. She is also a research affiliate in the Department of Mechanical Engineering at MIT. Daniela received her Ph.D. in Mechanical Engineering and Human-Computer Interaction from Iowa State University, and her B.S. and M.S. degrees in Mechanical 
Engineering from Bucknell University, Lewisburg, PA. Dr. Faas's research interest is in virtual reality, haptic interaction, design methods, and engineering education.

Qifang Bao is currently a Masters student in the Department of Mechanical Engineering at MIT. She earned her BS in mechanical engineering from Tsinghua University, Beijing, China. Bao's research interest is in design preferences, and the design of energy systems.

Daniel Frey is a Professor of Mechanical Engineering and Engineering Systems at MIT. His research concerns robust design of engineering systems. He holds a Ph.D. in Mechanical Engineering from MIT, an MS in Mechanical Engineering from the University of Colorado, and a BS in Aeronautical Engineering from Rensselaer Polytechnic Institute.

Maria Yang is the Robert N. Noyce Career Development Assistant Professor of Mechanical Engineering and Engineering Systems at MIT. She earned her SB from MIT and her MS and PhD from Stanford, both in Mechanical Engineering. Dr. Yang's research interest is in the process of designing products and systems. Her recent work explores the role of design representation in driving early stage design process. 